\title{
Les effets délétères du virilisme de jeunes élèves
}

doi:10.18162/fp.2018.a152

\section{HRONIQUE • Éthique en éducation}

On pourrait penser que les conduites violentes de virilité, dans les sociétés de l'égalité des sexes, étaient sur leur déclin. Que les hommes étaient disposés à se réconcilier avec l'univers féminin. Mais force est de croire que nombre d'hommes ont établi leur quartier dans le virilisme. Pensons notamment aux fanatiques du football qui forment des hordes de hooligans, aux courants de l'extrême droite composés essentiellement d'hommes à la virilité exacerbée ou encore aux soldats de l'État islamique qui bénéficient de l'esclavage sexuel des femmes. Le virilisme contemporain se manifeste par la domination des hommes sur les femmes, mais plus encore par le désir masculin de différenciation radicale avec l'univers féminin. Nous pensons que le virilisme est susceptible d'éclairer le rapport négatif à l'école de plusieurs jeunes garçons.

\section{Le virilisme scolaire}

Des élèves coincés dans une problématique d'hypervirilité préfèrent en finir le plus tôt possible avec l'école. Ils n'arrivent pas à se sentir bien dans leur rôle d'élève. L'univers scolaire ne les stimule pas. Ils adhèrent à des représentations négatives de la réussite scolaire. Leur culture viriliste est incompatible avec le goût d'apprendre. Ils croient erronément que la vie intellectuelle est pour l'élite et que l'amour de l'école est un sentiment féminin. Il y a donc lieu de s'intéresser aux effets délétères de leurs pratiques virilistes. 
Le mot virilité, qui provient de vir, signifie homme, mais aussi, force, courage et vaillance (Corbin, Courtine et Vigarello, 2011). La virilité est traditionnellement associée à la puissance sexuelle, à la force physique, aux valeurs guerrières et à la domination sur les femmes. Les conduites de virilité procurent aux hommes le sentiment d'appartenir à l'identité masculine. La virilité demeure un enjeu risqué, car les hommes doivent la faire reconnaître par d'autres hommes (Badinter, 1992). Un homme n'est jamais définitivement assuré sur sa virilité. Elle n'est jamais acquise et doit continuellement être prouvée. En fait, l'inquiétude masculine est ontologique à l'égard de sa virilité. C'est pourquoi Pierre Bourdieu écrit : «Le privilège masculin est aussi un piège [car elle impose] à chaque homme le devoir d'affirmer [...] sa virilité [...] au nom de l'honneur, sous le regard du groupe viril, craignant de perdre la face, l'admiration du groupe » (1998, p. 27).

Les concepts d'hypervirilité et de virilisme utilisés ici renvoient aux qualités, attributs et ressentis des garçons qui cherchent à montrer à tout prix, souvent par des conduites violentes, qu'ils n'ont rien de féminin. Ceux-ci affirment exagérément leur masculinité en faisant valoir qu'ils n'appartiennent pas à l'univers des femmes. Ces jeunes se sentent virils lorsqu'ils ont des attitudes, des manières d'être, des gestes, des désirs qui montrent qu'ils ne sont pas des femmes (Jeffrey, 2012). En somme, ces garçons considèrent que leur virilité est sauve tant qu'ils ne sont pas associés à quelque chose de féminin. Ils sont prêts à tout pour prouver qu'il n'y a rien de féminin en eux. C'est peu dire que leur rapport au féminin, à la féminité et aux femmes est problématique.

Ces jeunes qui proviennent majoritairement des classes populaires cherchent l'autorité d'un chef pour les mener. Il est connu que les classes populaires sont plus conservatrices et plus enclines à perpétuer les stéréotypes du genre. Les jeunes virilistes veulent des réponses définitives à leurs multiples questions existentielles. La culture réflexive les déstabilise. Ils vont aisément intégrer un groupe radical, soit-il politique, sportif ou religieux (Jeffrey, 2017). Leur virilisme est une sorte de carapace censée protéger leur fragilité et leurs blessures intérieures. Ces jeunes refusent l'introspection, le regard intérieur, la culture de l'intériorité. Ils prennent plaisir à cultiver des images virilistes qui vitalisent leur narcissisme de groupe. Ils refusent les acquis de la société égalitaire et font la promotion des stéréotypes de la masculinité patriarcale. Ces garçons de l'hypervirilité ont peur d'apparaître devant d'autres garçons comme faibles, efféminés, impuissants et homosexuels. Cette peur témoigne du coup de leur mal de vivre.

Ces jeunes garçons construisent donc leur identité masculine par opposition avec l'identité féminine (Héritier, 1996). S'ils considèrent que les femmes aiment danser, alors ils ne danseront pas. S'ils pensent que les filles sont dociles, alors ils seront rebelles. Ils affirment et ressentent leur virilité par l'entremise de pratiques de différenciation extrême avec le féminin. En fait, avec des représentations très stéréotypées qu'ils ont de la féminité. Ils se sentent obligés de continuellement prouver leur virilité aux yeux de leurs pairs, comme s'ils n'en étaient eux-mêmes jamais tout à fait convaincus.

Cet imaginaire de l'hypervirilité est hérité d'un patriarcat qui impose une logique de la domination masculine. Le sentiment de virilité outrancier, dès lors, se renforce dans les situations où un garçon est en position de domination sur les filles et sur d'autres garçons. Pour les jeunes virilistes, les garçons les plus vulnérables se retrouvent du côté féminin. Les élèves le moindrement efféminés sont stigmatisés. Les virilistes s'acharnent sur les garçons qui sont les plus sympathiques aux femmes et au monde scolaire. Pour eux, une femme est un objet sexuel voué à leur plaisir. Ils croient que leurs attitudes viriles 
sont des éléments de séduction qui intéressent toutes les femmes. Ils placent, comme nous le verrons, le monde scolaire du côté du féminin.

\section{Le virilisme scolaire}

L'hypothèse retenue ici est que plus un jeune garçon se conforme à un stéréotype masculiniste (Blais et Dupuis-Déri, 2018), plus il met en scène des comportements qui montrent une aversion de l'école considérée par eux comme féminine. Jean-Claude Saint-Amant avait réalisé que plus les jeunes garçons se conforment à des stéréotypes masculins virilistes, moins ils performent à l'école : « le conformisme de certains garçons sur le plan de leurs représentations des identités de sexe les amène, dans la pratique, à reléguer au second plan les attitudes et comportements associés à la réussite éducative » (2007, p. 62). Ils vont développer un discours et des pratiques anti-scolaires. Certains d'entre eux iront jusqu'à manifester une aversion de l'école et des apprentissages. Les plus radicaux dans le virilisme diront que les études sont pour les filles, les nerds, les bolés. Les garçons qui aiment lire et écrire leur servent de repoussoir. L'école est en effet pour eux un antre féminin dont ils cherchent à s'exclure le plus tôt possible. En somme, ils vont déconsidérer les études et les qualités de ceux qui réussissent avec brio leur scolarité. Ils refusent de mettre des efforts au travail pour apprendre. Les jeunes virilistes qui réussissent soutiendront qu'ils nont pas étudié, signifiant que le cerveau des hommes est «instinctivement » supérieur à celui des femmes qui elles, doivent travailler pour réussir. Ils entretiennent une peur de bien paraître à l'école, de passer pour un élève qui étudie et qui réussit.

On peut imaginer que la virilité exacerbée de ces jeunes est fragile, vacillante et défaillante. Leur désir de se soustraire à l'univers féminin est signe qu'une part féminine en eux n'arrive pas à se taire. Ce dont ils tiennent à se séparer, à s'opposer, peut-on supposer, est la part féminine qu' ils portent. On peut penser à un amour inconditionnel de la mère ou à la crainte d'être incapable de devenir homme en s'extirpant d'un désir fusionnel maternel. Leur virilité devient d'autant plus oppressive qu'ils se sentent menacés par le féminin. Quoi qu'il en soit, car l'étiologie montre des causes multiples, ces jeunes garçons devront se distancier de leurs conduites virilistes et trouver la paix avec l'univers féminin.

Pour montrer leur aversion du monde scolaire, certains jeunes virilistes multiplient les conduites d'indiscipline et d'incivilité. Confronter un enseignant ou le narguer constitue pour eux des signes de virilité. Perturber la classe et déranger les autres rassurent également leur sentiment de virilité. L'affirmation virile peut expliquer leur violence, leur sexisme, leur misogynie, leur homophobie, leur attachement aux valeurs traditionnelles du patriarcat, leur sentiment de supériorité et leur antiintellectualisme. Ils vont valoriser les réactions pulsionnelles, la spontanéité du corps pulsionnel et les décharges émotives qui leur apparaissent comme des émanations de leur nature masculine. Ils vont délibérément utiliser une langue grossière et ordurière censément plus authentique. À cet égard, leur manque de discipline corporelle est ahurissant. Leur virilisme les encarcane dans des attitudes boudeuses, irritables et dissipées à la Donald Trump. Certains d'entre eux développent une cruauté machiste qui se caractérise par des attaques sournoises contre tous les objets qui représentent l'école.

Sylvie Ayral, dans La fabrique des garçons, montre que les jeunes virilistes collectionnent les sanctions scolaires comme les sportifs cumulent des médailles. Pour impressionner leurs copains, certains d'entre eux se comportent pour être expulsés de l'école. Réussir est plutôt mal vu pour plusieurs de ces jeunes 
garçons, mais provoquer l'échec est vécu comme une preuve de virilité. Un élève viriliste va recevoir avec une grande gêne un bon résultat scolaire ou de bons mots de la part d'un enseignant. Son embarras provient du fait qu'il pourrait perdre la face devant les amis. Une bonne note devient objet de honte alors qu'une mauvaise note devient un bienfait. La pression du groupe de pairs est déterminante dans le désir de réussir ou d'échouer.

Toutefois, certains d'entre eux développent des stratégies pour concilier la réussite scolaire avec leur culture viriliste. Ils vont obtenir des notes de passage dans toutes les matières. S'ils ont un bon résultat dans un cours, ils pourront dire aux copains que c'est dû au hasard, qu'ils ont triché ou qu'ils ont trompé l'enseignant. La tricherie est vue comme une conduite acceptable, car elle signifie pour eux que l'enseignant n'a pas l'intelligence de la détecter. Par conséquent, qu'ils sont supérieurs, virilement parlant, à leur enseignant.

Les jeunes garçons qui s'identifient à la culture viriliste peuvent contaminer le climat scolaire. Leur opposition au monde scolaire influence d'autres jeunes qui pourraient réussir leurs études. De plus, les virilistes ont souvent des comportements d'intimidation à l'égard des garçons qui s'intéressent à l'école, ce qui en décourage plus d'un. En fait, comment un jeune connu pour sa passion littéraire peut-il se protéger contre les agressions verbales et physiques des jeunes virilistes qui ne pourront quitter l'école avant seize ans? Comment peut-il manifester publiquement un désir d'apprendre sans se faire ridiculiser par les virilistes? Comment peut-il éviter de se faire traiter de " fifi » ou de " pédé » parce qu'il aime lire? Le phénomène de l'intimidation des garçons qui aiment l'école est suffisamment important pour qu'on le prenne au sérieux. Pourtant, l'école publique ne tient pas compte de la pression viriliste que subissent les jeunes garçons.

\section{Conclusion}

Il y a lieu de penser que le virilisme constitue une contrainte importante à la réussite scolaire des garçons. Si des jeunes élèves virilistes aiment l'école et veulent réussir leurs études, ils devront le cacher à leur groupe d'amis sous peine d'être ridiculisés et exclus. D’autres garçons savent que la réussite scolaire peut les amener à être victimes d'intimidation. Ils ont réellement peur d'être malmenés par ces garçons virilistes qui s'opposent à la culture scolaire. Ils étudient en cachette, loin du regard de ceux qui croient que l'école est dévirilisante.

Comment peuvent-ils s'en sortir lorsque la réussite scolaire les place en situation de victimes? Que doivent-ils faire lorsque la réussite les condamne au mépris? On sait que le fait d'être un garçon augmente les risques d'échec scolaire. Mais a-t-on déjà réalisé les effets obsolètes de la culture viriliste sur les jeunes garçons de l'école publique! Maintenant, il nous reste à trouver des stratégies pour contrer la culture viriliste, ou bien encore montrer à ces jeunes qu'il est viril de lire, d'étudier, d'apprendre et de réussir ses études. Comment leur communiquer que des hommes cultivés, formés dans les grandes universités, n'ont rien perdu de leur virilité? Que les astronautes canadiens sont des hommes virils! Comment amener ces jeunes garçons qui refusent l'école pour des raisons virilistes à développer le sentiment que l'entrée dans la culture intellectuelle ne les déleste pas de leur virilité? 
Simone de Beauvoir avait bien compris que les hommes également sont appelés à construire leur identité masculine. "La célèbre philosophe soulignait elle-même que sa célèbre formule du Deuxième sexe demandait à être complétée par son pendant "on ne naît pas homme, on le devient" " (Baubérot, 2011, p. 159). La virilité, disait Beauvoir, n'est pas donnée au départ. Devenir homme est un lent processus de socialisation. Le problème étant que les représentations ancestrales de la virilité ne sont plus en adéquation avec notre époque.

\section{Références}

Ayral, S. (2011). La fabrique des garçons : sanctions et genre au collège. Paris : Presses universitaires de France.

Badinter, É. (1992). XY. De l'identité masculine. Paris : Odile Jacob.

Baubérot, A. (2011). On ne naît pas viril, on le devient... Dans A. Corbin, J.-J. Courtine et G. Vigarello (dir.), Histoire de la virilité (tome III, p. 159-184). Paris : Seuil.

Blais, M. et Dupuis-Déri, F. (dir.) (2018). Le mouvement masculiniste au Québec : l'antiféminisme démasqué. Montréal, QC : Éditions du Remue-ménage.

Bourdieu, P. (1998). La domination masculine. Paris : Seuil.

Corbin, A., Courtine, J.-J. et Vigarello, G. (dir.). (2011). Histoire de la virilité. Paris : Seuil.

Héritier, F. (1996). Masculin/féminin. La pensée de la différence. Paris : Odile Jacob.

Jeffrey, D. et Lachance, J. (2012). Les rites de virilisation. Dans D. Jeffrey et J. Lachance (dir.), Codes, corps et rituels dans la culture jeune (p. 139-154). Québec, QC : Presses de l'Université Laval.

Jeffrey, D. (2017). La culture de la mort chez les jeunes djihadistes. Frontières, 29(1). http://dx.doi.org/10.7202/1042983ar

Saint-Amant, J.-C. (2007). Les garçons et l'école. Montréal, QC : Sisyphe.

\section{Pour citer cet article}

Jeffrey, D. (2018). Les effets délétères du virilisme de jeunes élèves. Formation et profession, 26(3), 127-130. http://dx.doi.org/10.18162/fp.2018.a152 